\title{
Factors (TAFs) required for activated transcription interact with TATA box-binding protein conserved core domain
}

\author{
Qiang Zhou, Thomas G. Boyer, and Arnold J. Berk ${ }^{1}$ \\ Molecular Biology Institute, Department of Microbiology and Molecular Genetics, University of California, Los Angeles, \\ Los Angeles, California 90024-1570 USA
}

\begin{abstract}
TFIID is a multisubunit protein containing the TATA box-binding polypeptide (TBP) and associated factors (TFIID-TAFs) required for activated transcription by RNA polymerase II. TBPs from different eukaryotes contain a highly conserved carboxy-terminal domain and very divergent amino-terminal domains. Earlier studies proposed that the amino-terminal domains of metazoan TBPs are required for activated transcription. However, we report that a human TFID complex containing an amino-terminal truncated TBP contains all the major TFIID-TAFs and supports in vitro transcriptional stimulation by different classes of activation domains and from a TATA-less promoter. Protein blotting experiments revealed direct interactions between the conserved domain of TBP and the two largest TAFs. The results suggest a model for the interaction of TFIID-TAFs with TBP.
\end{abstract}

[Key Words: TFIID; RNA polymerase II; transcription factor; transcriptional activation; TBP-associated factors]

Received November 17, 1992; revised version accepted December 14, 1992.

The TATA box-binding polypeptide (TBP) is required for transcription by all three nuclear RNA polymerases in eukaryotes (for review, see Sharp 1992; White and Jackson 1992). In higher eukaryotes the association of TBP with transcription by the different polymerases appears to be determined by its interaction with tightly associated polypeptides called TAFs (for TBP-associated factors; for review, see Pugh and Tjian 1992). Historically, the TBP complexes involved in RNA polymerase II transcription have been called TFIID (Matsui et al. 1980). Isolated TBP can function with the other polymerase II general transcription factors in basal level in vitro transcription from a TATA box promoter, but the TAFs associated with TBP in TFIID are required for transcriptional activation by activator proteins (Dynlacht et al. 1991; Tanese et al. 1991). Recently, TFIID activity from HeLa cells was shown to reside in what appears to be a single purified multisubunit complex of $\sim 700 \mathrm{kD}$, termed holo-TFIID, composed of TBP and several TAFs ranging in size from $\sim 250$ to $28 \mathrm{kD}$ (Zhou et al. 1992). Holo-TFIID was shown to support in vitro transcriptional activation by several classes of activation domains and from a polymerase II promoter lacking a TATA box.

Complementary DNAs encoding the TBP have been cloned from yeasts, insects, plants, and mammals

${ }^{1}$ Corresponding author.
(Greenblatt 1991; Pugh and Tjian 1992). The carboxyterminal $\sim 180$ residues of TBP are $>80 \%$ identical in all organisms and form a protease-resistant domain that binds TATA boxes and is active for basal polymerase II transcription in vitro (Horikoshi et al. 1990; Lieberman et al. 1991). The amino-terminal domains of TBPs from these organisms differ significantly in length and sequence. A recent crystal structure of a TBP from Arabidopsis thaliana shows that the conserved carboxyl terminus folds into two symmetrical subdomains with the amino-terminal domain extending to one side (Nikolov et al. 1992).

Early in vitro experiments with cloned Drosophila and human TBP indicated that the "species-specific amino terminus" is required for the stimulation of transcription by the activator protein $\mathrm{Spl}$ that has glutamine-rich activation domains (Peterson et al. 1990; Pugh and Tjian 1990). However, later molecular genetic studies in yeast revealed that the species-specific amino-terminal domain of yeast TBP is not required for viability (Cormack et al. 1991; Gill and Tjian 1991; Reddy and Hahn 1991; Poon et al. 1991; Zhou et al. 1991). At first it seemed surprising that transcriptional activation might function through a different mechanism in yeast than in higher eukaryotes. However, Kelleher et al. (1992) recently reported that in both yeast and human in vitro transcription systems, either yeast or human TBPs, which have highly divergent amino-terminal domains, can support 
activation by Gal4-VP16 and GCN4. GAL4-VP16 and GCN4 have acidic activation domains that function in vivo in both yeast and higher eukaryotes, whereas the glutamine-rich activation domain of $\mathrm{Spl}$ does not function in yeast (cited in Pugh and Tjian 1992). This finding appeared to resolve the apparent conflict between the requirement of the human and Drosophila TBP aminoterminal domains for $\mathrm{Spl}$ activation and the lack of a requirement for the yeast amino-terminal TBP domain for yeast cell viability. It seemed that in both yeast and higher eukaryotic systems acidic activation domains required only the conserved domain of TBP to function, whereas activation through glutamine-rich activation domains required a mechanism developed in higher eukaryotes and absent in yeast, which depended on the much larger TBP amino-terminal domains present in these organisms.

Because TAFs are required for transcriptional activation and the amino-terminal domain of human TBP was thought to be required for $\mathrm{Spl}$ activation, we asked whether one or more TAFs associate specifically with the amino-terminal domain of human TBP to mediate activation by glutamine-rich activation domains. To address this question, we expressed an amino-terminal deleted form of TBP in HeLa cells and analyzed the TAFs associated with the deleted TBP polypeptide. We found that all the major TAFs associated with holo-TFIID also associated with the amino-terminal deleted form of TBP. Additional analyses of protein-protein interactions between TBP and immobilized TAFs confirmed that all detectable interactions were through the TBP conserved carboxy-terminal domain. Moreover, in contrast to the initial conclusion that the species-specific amino terminus of TBP is required for transcriptional activation by $\mathrm{Spl}$, we found that purified holo-TFIID complex assembled with the amino-terminal deleted form of TBP fully supported in vitro transcriptional activation by all activators tested including $\mathrm{Sp} 1$. These observations together with the discovery of specific interactions between the TBP core domain and specific TFIID-TAFs allow us to refine a molecular model of the TFIID complex.

\section{Results}

\section{Expression of amino-terminal-deleted TBP in} HeLa cells

A gene encoding an epitope-tagged (Field et al. 1988) TBP mutant (e $\Delta$ NTBP) was stably introduced into HeLa cells using a retrovirus vector (Muller et al. 1991). The e $\triangle$ NTBP mutant has a deletion of residues 1-154, removing nearly the entire amino-terminal domain. (The first residue in the conserved core of human TBP is residue 159.) A 9-residue epitope recognized by monoclonal antibody $12 \mathrm{CA} 5$ was appended to the amino terminus to facilitate purification (Field et al. 1988). Clones of transformed HeLa cells expressed varying levels of e $\triangle$ NTBP (Fig. 1, lanes 2-9|. Further experiments were performed with clone 20 (lane 9) in which the level of e $\triangle$ NTBP is $\sim 10-20 \%$ the concentration of the epitope-tagged form of full-length TBP (eTBP) in clone LTR $\alpha 3$ (lane 1; Zhou

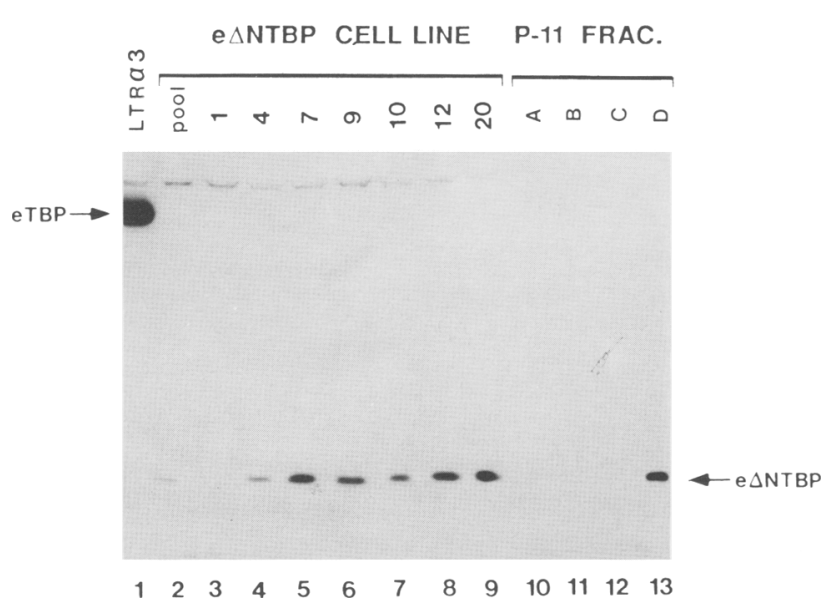

Figure 1. Clones of transformed cells expressing e $\triangle$ NTBP. Extracts of LTR $\alpha 3$ cells expressing full-length eTBP (Zhou et al. 1992; lane 1), extracts of e $\Delta$ NTBP-expressing cell lines (lanes 2-9), and phosphocellulose fractions A, B, C, and D (Dignam et al. 1983; $30 \mu \mathrm{g}$ each, lanes 10-13) prepared from cell line 20 nuclear extract were subjected to SDS-gel electrophoresis on a $11 \%$ polyacrylamide gel and subjected to Western blotting with monoclonal antibody 12CA5. Lane 2 contains extract from a pool of G418-resistant cell lines generated with the e $\Delta$ NTBP retrovirus vector. The positions of $\mathrm{eTBP}$ and $\mathrm{e} \triangle \mathrm{NTBP}$ are shown.

et al. 1992). This represents $\sim 7-15 \%$ of total TBP in clone 20 cells.

The nuclear extract was prepared from clone 20 cells, fractionated by chromatography on a phosphocellulose column (Dignam et al. 1983), and the resulting fractions analyzed by Western blotting with monoclonal antibody 12CA5 (Fig. 1, lanes 10-13). The highest concentration of e $\triangle$ NTBP was found in the D fraction $(0.5-1.0 \mathrm{M} \mathrm{KCl}$ fraction), similar to the full-length TBP protein present in the parental HeLa cells (data not shown). Isolated human TBP and its carboxy-terminal domain elute from phosphocellulose at a lower salt concentration (Peterson et al. 1990). Consequently, the elution profile of e $\Delta$ NTBP expressed at low level in clone 20 cells suggests that it had become associated with the TAF(s) responsible for the relatively salt-stable interaction of the TFIID complex with phosphocellulose.

\section{$\triangle N T B P$ binds to the same TFIID-TAFs as full-length $T B P$}

A multisubunit protein complex containing e $\triangle$ NTBP was affinity purified from the phosphocellulose $D$ fraction of clone 20 cells using a column of 12 CA5 monoclonal antibody followed by elution with synthetic epitope peptide (Field et al. 1988), as described for fulllength epitope-tagged TBP (Zhou et al. 1992). This protein complex (referred to as eANTFIID) and the eTFIID complex containing epitope-tagged full-length TBP were analyzed by SDS-polyacrylamide gel electrophoresis and silver staining (Fig. 2). Significantly, the eANTFIID fraction contained each of the TAFs found associated with full-length eTBP. The low molecular weight e $\triangle$ NTBP 


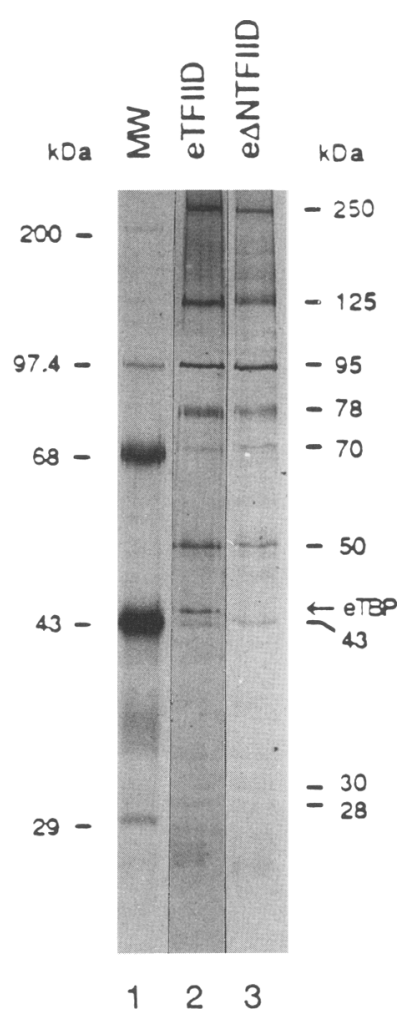

Figure 2. Comparison of purified eANTFIID complex and eTFIID complex. A silver-stained $11 \%$ SDS-polyacrylamide gel is shown. Lane 1 contains molecular weight markers. Lane 2 shows eTFIID eluted with HAl peptide from a $12 \mathrm{CA} 5$ monoclonal antibody affinity column incubated with the phosphocellulose D fraction of LTR $\alpha 3$ cells (Zhou et al. 1992). Lane 3 shows e $\triangle N T F I D$ complex eluted from the affinity column incubated with the phosphocellulose D fraction of e $\Delta$ NTBP-expressing cell line clone 20 . The $30-$ and $28-\mathrm{kD}$ TAFs reported earlier (Zhou et al. 1992) are difficult to see in this reproduction.

subunit was not visible on this silver-stained gel, but was detected readily by Western blotting using the monoclonal antibody $12 \mathrm{CA} 5$ (see Fig. $4 \mathrm{C}$ ). It is difficult to determine the stoichiometry of the different TAFs in eTFIID and e $\Delta$ NTFIID from silver-stained gels (e.g., Figs. 2 and 4) because different polypeptides stain to different extents and the relative stain intensities vary somewhat from gel to gel. On the basis of the appearance of several silver-stained gels of these purified proteins, we do not believe the stoichiometry of the TAFs to TBP is different for full length and $\triangle$ NTBP, but we cannot rule out this possibility.

This and other preparations of eANTFIID clearly revealed a 43-kD TAF that was not visualized earlier (Zhou et al. 1992), probably because it migrates close to eTBP on SDS-polyacrylamide gels. We questioned whether this 43-kD polypeptide might be the endogenous TBP in clone 20 cells. This would be possible if the TFIID complex contained two copies or more of TBP per complex. This is an important point because if the $43-\mathrm{kD}$ polypeptide were TBP, some of the TAFs might be associated with the purified eANTFIID through the amino-terminal domain of the full-length TBP. However, a rabbit polyclonal serum that recognizes human TBP (Lee et al. 1991) failed to detect the $43-\mathrm{kD}$ polypeptide in Western blots (data not shown). Because the eANTFIID complex preparation did not contain the amino-terminal domain of TBP but did contain each of the major TFIID TAFs, we conclude that the species-specific amino terminus of human TBP is not required for the interaction between TBP and the major TAFs in TFIID.

\section{Interaction of TBP with immobilized TAFs}

To confirm and extend this result, interactions between TBP and TAFs were analyzed using a Far-Western protein blotting assay (Lee et al. 1991; Fig. 3). Purified eTFIID complex was subjected to SDS-gel electrophoresis, blotted onto nitrocellulose, subjected to a protein renaturation protocol, and probed with ${ }^{35} \mathrm{~S}$-labeled fulllength TBP or TBP deletion mutants TBP $\triangle \mathrm{C} 273$, TBP $\triangle \mathrm{C} 167$, or TBP $\triangle \mathrm{N} 157$, as diagramed in Figure $3 \mathrm{~A}$. Figure $3 \mathrm{C}$ shows that the two largest TAFs $\mathrm{TAF}_{250}$ and $\mathrm{TAF}_{125}$ ) were specifically bound by full-length TBP. These two TAFs were also bound by the amino-terminal truncated TBP derivative TBP $\triangle N 157$, but not by a TBP deletion mutant lacking almost the entire carboxy-terminal conserved domain (TBP $\triangle$ C167). TBP $\Delta$ C167 failed to interact with any TAF on the blot. Moreover, when part of the second imperfect direct repeat of TBP (for review, see Greenblatt 1991) was removed from the conserved domain, the resulting mutant TBP $\triangle \mathrm{C} 273$ recognized $\mathrm{TAF}_{125}$ but not $\mathrm{TAF}_{250}$.

In control experiments, none of the TAFs were bound by in vitro translated brome mosaic virus (BMV) coat protein, which has a high isoelectric point similar to that of human TBP (data not shown). This indicates that the interactions between TBP and TAFs detected in this protein-blotting experiment were not due to simple nonspecific electrostatic interactions. The specificity of the interactions is also demonstrated by the observation that TBP $\Delta 273$, which contains the TBP basic repeat region, is bound to $\mathrm{TAF}_{125}$ but not to $\mathrm{TAF}_{250}$. These Far-Western results are consistent with the analysis above of TAFs associated with $\mathrm{e} \triangle \mathrm{NTBP}$ in vivo. Interactions were detected between TAFs and the conserved carboxy-terminal domain of TBP, but not with the TBP amino-terminal domain.

\section{$\triangle N T F I D$ supports activated transcription and transcription from a promoter lacking a TATA box}

These results indicated that the amino-terminal domain of human TBP is not required for TBP binding to the major TFIID-TAFs. However, it seemed possible that minor TAFs not visualized on our gels might be required for activation by some activator proteins. Consequently, it was important to test the transcriptional activity of the eANTFIID complex fraction. The activity of e $\triangle$ NTFIID was analyzed in in vitro transcription reactions reconstituted with partially purified general tran- 
A

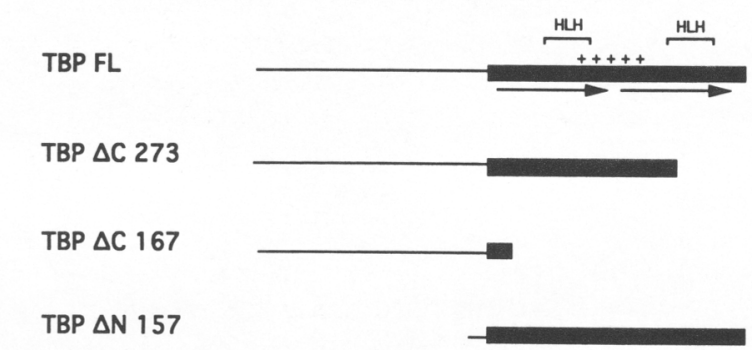

B

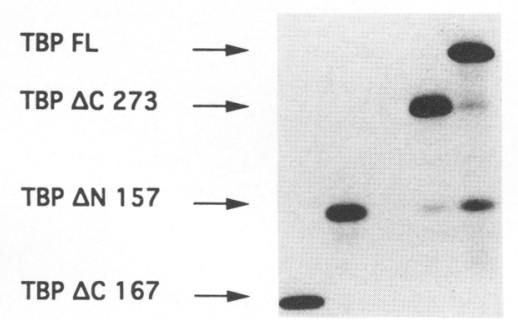

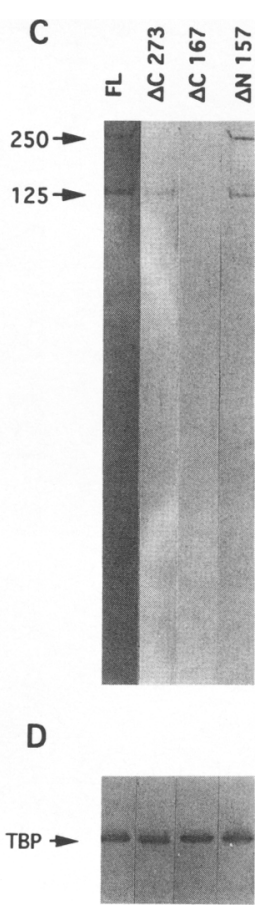

Figure 3. Far-Western protein-blotting analysis of the interaction between TBP and TBP-associated factors (TAFs). (A) Diagrams of the primary structures of the full-length TBP and three TBP deletion mutants. The rectangle represents the conserved carboxy-terminal domain. Arrows represent the two imperfect direct repeats. Positive signs indicate the basic repeat region, $\mathrm{HLH}$, potential helix-loophelix motifs. $(B)$ SDS-PAGE analysis of the full-length TBP and three TBP deletion mutants. Proteins were expressed in a rabbit reticulocyte lysate in vitro translation system in the presence of Trans ${ }^{35} \mathrm{~S}$-Label (ICN). (C) Equal amounts of the eTFIID complex was subjected to SDS-gel electrophoresis, blotted onto nitrocellulose, subjected to a renaturation protocol and incubated with equal cpm of ${ }^{35} \mathrm{~S}$-labeled fulllength TBP, TBP $\Delta \mathrm{C} 273$, TBP $\Delta \mathrm{C} 167$, or TBP $\Delta$ N157 preparations shown in $B$. An autoradiogram of the washed blots is shown. The positions of $\mathrm{TAF}_{250}$ and $\mathrm{TAF}_{125}$ are indicated by arrows. $(D)$ Western analysis of the same nitrocellulose blots shown in $C$ using monoclonal antibody 12CA5 specific for eTBP, demonstrating that the same amount of the eTFIID complex was on each of the blot strips. scription factors. The first activator tested was GAL4$\mathrm{AH}$, which contains an acidic activation domain (Giniger and Ptashne 1987). The template, pG5E4T (Carey et al. 1990), contained five Gal4-binding sites upstream of the adenovirus E4 TATA box and the initiation region. Activation by Gal4-AH requires one or more TAFs, as activation is observed in reactions with eTFIID complex, but not with recombinant TBP (Zhou et al. 1992).

In the absence of any source of TFIID activity, no specific transcription could be detected (Fig. 4A, lanes 1-2). Significantly, addition of eANTFIID supported GAL4$\mathrm{AH}$ activated transcription (lane 6) to the same extent as the eTFIID fraction (lane 4). The amounts of eANTFIID and eTFIID used in these reactions were assayed by gel electrophoresis and silver staining (Fig. 4B), and by Western blotting with monoclonal antibody $12 \mathrm{CA} 5$ (Fig. 4C).

On the basis of these silver-staining and Western blotting results, we estimate that the amount of e $\triangle$ NTFIID protein used in the transcription reaction was within a factor of two of the amount of eTFIID used. (From the Western blotting result the amount of e $\triangle \mathrm{NTBP}$ appeared to be $\sim 50 \%$ the amount of eTBP (Fig. 4 C), whereas the silver-stained gel (Fig. 4B) indicated slightly more e $\Delta$ NTFIID protein compared with eTFIID protein. We think these slight variations are due, on the one hand, to differences in transfer of polypeptides of different size in Western blotting, and on the other hand, to variations in recovery and staining of polypeptides in the SDS gel.) Given the limitations of these techniques to measure the low protein concentrations involved we conclude that the eANTFIID fraction had similar (within a factor of two) transcriptional-specific activity as the eTFIID fraction for GAL4-AH activated transcription.

Next, we tested whether purified e $\Delta$ NTFIID could support transcriptional activation by $\mathrm{Spl}$. As a stringent test of $\mathrm{Sp} 1$ activation we assayed transcription from a promoter lacking a TATA box. It was shown previously (Smale et al. 1990; Pugh and Tjian 1991; Zhou et al. 1992) that one or more TAFs are required for transcription from a template lacking a TATA box but containing the initiator element of the terminal transferase gene (Smale and Baltimore 1989) and upstream Spl-binding sites. The eANTFIID fraction supported Spl activated transcription from this TATA-less promoter with similar specific activity to that observed for the eTFIID complex (Fig. 5). The e $\Delta$ NTFIID fraction also supported Sp1activated transcription from a promoter containing a TATA box and transcriptional activation by the Zta transcription factor encoded by Epstein-Barr virus, assayed as described earlier (Zhou et al. 1992; data not shown).

\section{Discussion}

In contrast to what has been widely believed on the basis of early studies with cloned human and Drosophila TBP, the experiments reported here demonstrate that the species-specific amino terminus of human TBP is not re- 
A
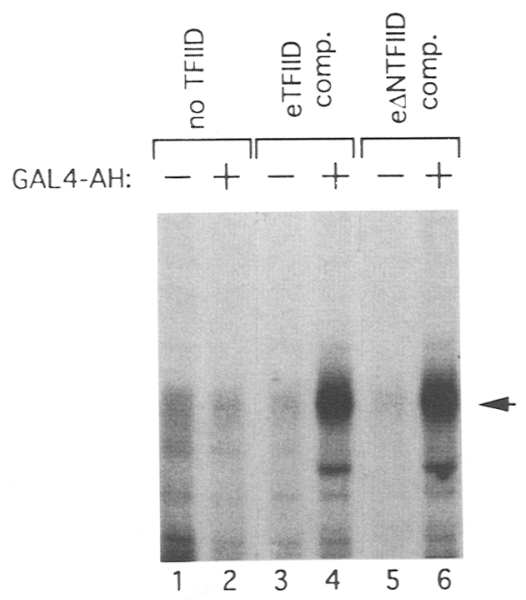

B

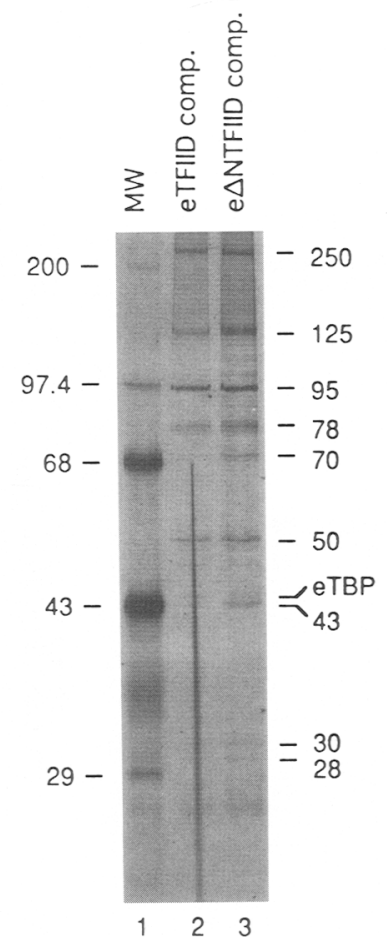

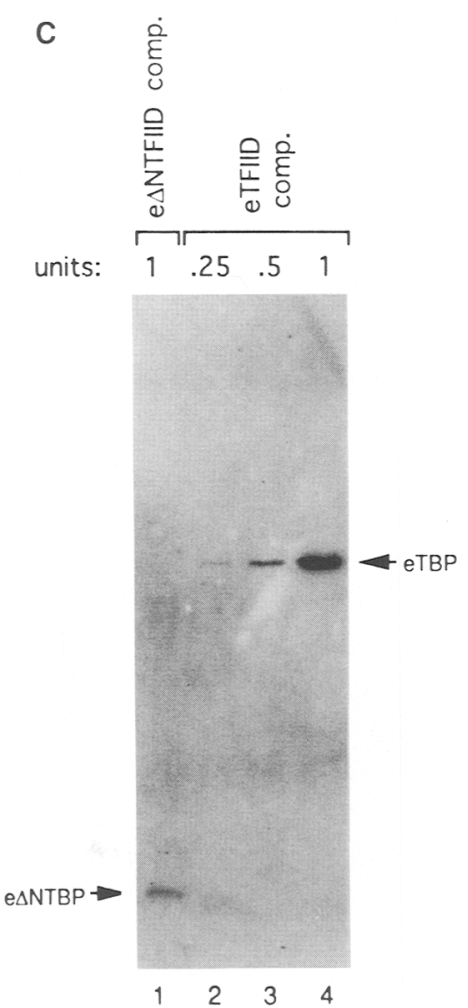

Figure 4. e $\triangle$ NTFIID complex supports GAL4-AH stimulated transcription. (A) Primer extension assays of reconstituted in vitro transcription. Reactions in the absence (-) or presence (+) of GAL4-AH are shown with the indicated sources of TFID activity. The template contained five GAL4-binding sites upstream of the adenovirus E4 TATA box and initiation region. The arrowhead marks the position of the major specific transcripts. (B) The amounts of eTFIID and e $\triangle$ NTFIID used in the transcription reactions shown in $A$ were analyzed by SDS-polyacrylamide gel electrophoresis and silver staining. $(C)$ The amounts of eTFIID and e $\Delta$ NTFIID used in the transcription reactions shown in $A$ were designated as one unit. The indicated units of either the eTFIID or e $\Delta$ NTFIID fractions were subjected to Western blotting using monoclonal antibody $12 \mathrm{CA} 5$.

quired for transcriptional trans-activation by three different activator proteins tested. These activators have different classes of activation domains: $\mathrm{Spl}$ contains glutamine-rich activation domains (Courey and Tiian 1988); Gal4-AH has an acidic activation domain /Giniger and Ptashne 1987); Zta contains an activation domain that is not particularly rich in any one amino acid residue (for discussion, see Lieberman and Berk 1990). The aminoterminal domain of TBP was also found to be dispensable for transcription from a promoter lacking a TATA box.

Analysis of the TAFs associated with the conserved core domain of TBP provides a molecular explanation for why the species-specific amino-terminus is dispensable for activated transcription. TAFs are required for transcriptional activation by all activator proteins tested (Dynlacht et al. 1991; Tanese et al. 1991; Zhou et al. 1991), and the TBP conserved core domain associates with all the TAFs complexed to full-length TBP (Fig. 2). These results emphasize the importance of the TAFs in the mechanism of activation.

Our results also resolve what initially appeared to be a contradiction between studies of TBP in yeast and higher eukaryotes. The conclusion that the species-specific amino termini of human and Drosophila TBPs were re- quired for transcriptional activation (Pugh and Tjian 1990; Peterson et al. 1990) seemed at odds with the observation that the amino-terminal domain of yeast TBP is not required for viability /Cormack et al. 1991; Gill and Tjian 1991; Reddy and Hahn 1991; Poon et al. 1991; Zhou et al. 1991). Initially it seemed that despite the remarkable conservation of many of the features of RNA polymerase II transcription among all eukaryotes, the mechanism of transcriptional activation might be fundamentally different in yeast and metazoans. The finding of Kelleher et al. (1992) that both yeast and human TBP supported in vitro activation by GAL4-VP16 and GCN4 went a considerable way in dispelling the apparent discrepancy, as it argued that the TBP core domain is sufficient for activation by acidic activation domains. The new result that the amino-terminal domain of TBP can be entirely deleted without affecting activation by Spl, the activator used in the initial studies suggesting the importance of the TBP amino-terminal domain, argues that the mechanisms of activation in yeast and higher eukaryotic systems are in fact likely to be highly homologous. Moreover, our finding that the conserved carboxy-terminal domain of human TBP associates with the full set of TFIID-TAFs makes it seem very likely 


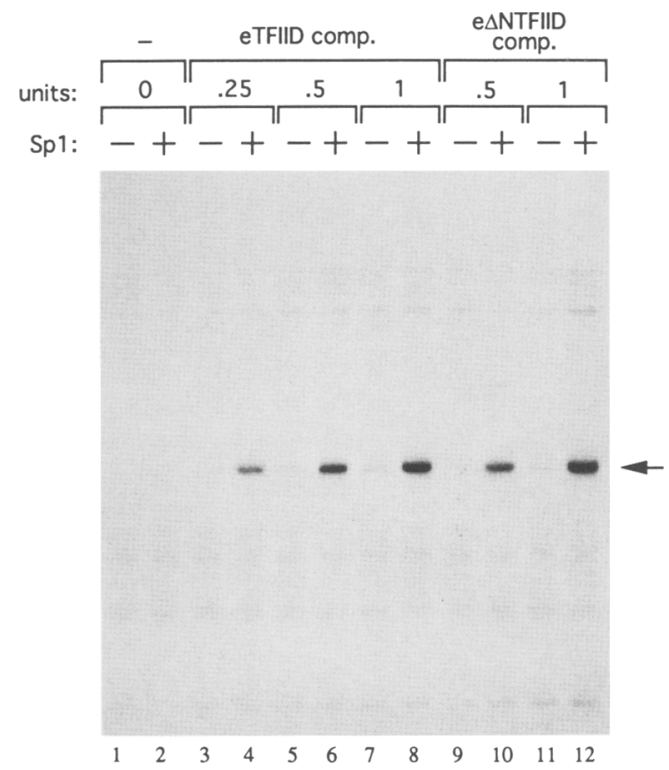

Figure 5. e $\Delta$ NTFIID complex supports Spl-activated transcription from a promoter lacking a TATA box. The template used in these reconstituted in vitro transcription reactions (plasmid VI; Smale et al. 1990) contains the Spl binding SV40 21 base-pair repeat region $42 \mathrm{bp}$ upstream of the terminal transferase gene initiator element (Smale and Baltimore 1989). The sources of TFIID activity are indicated. The units of eTFIID and e $\Delta$ NTFIID were the same as for Fig. $4 \mathrm{C}$. Spl purified by three cycles of affinity chromatography (Kadonaga and Tjian 1986) was added to the transcription reactions as indicated $(+)$.

that the highly homologous yeast TBP core domain interacts with a similar set of yeast TAFs in the process of polymerase II transcriptional activation.

The earlier experiments that suggested that the amino-terminal domain of human TBP is required for activated transcription used unfractionated nuclear extracts in which TFIID activity was heat inactivated (Peterson et al. 1990). Addition of full-length TBP partially restored activated transcription, whereas the conserved core domain did not. In hindsight, it seems likely that the full-length TBP must have reassociated with one or more TAFs required for activated transcription, whereas the conserved core domain did so less efficiently. Consequently, the amino-terminal domain may increase the association of TAFs with TBP in vitro under the conditions of these earlier experiments. However, our findings indicate that the amino terminus is not required for the assembly of functional TFIID complex in vivo. Recent transfection studies have also found that the amino-terminal domain of human TBP is not required for TBP to synergize with the $\beta$-retinoic acid receptor in vivo (Berkenstam et al. 1992).

Although the region amino-terminal to the conserved core domain varies greatly between TBPs isolated from different phyla; the amino-terminal domain of murine TBP is $>90 \%$ identical to human TBP (Tamura et al. 1991). This high conservation among mammals suggests that the amino-terminal region does perform a significant function. Although we found that the amino termi- nus of human TBP is not required for activated transcription by RNA polymerase II in vitro, we noted in earlier in vivo studies that deletion of the amino-terminal region of yeast TBP decreased induction from some inducible promoters (Zhou et al. 1991). Also, TBP participates in specific transcription initiation by each of the three eukaryotic RNA polymerases (Sharp 1992; White and Jackson 1992). Perhaps the amino-terminal domain of TBP has an important function in transcription by RNA polymerase I or III.

The Far-Western protein-blotting analysis (Fig. 3) demonstrated that the TBP conserved core domain interacts directly with the two largest TFIID-TAFs, TAF $_{250}$ and $\mathrm{TAF}_{125}$. The carboxy-terminal 66 residues are required for TBP binding to $\mathrm{TAF}_{250}$, but not for binding to $\mathrm{TAF}_{125}$. These results suggest a model in which the remaining lower molecular weight TAFs interact with TBP indirectly, through $\mathrm{TAF}_{250}$ and $\mathrm{TAF}_{125}$. However, we emphasize that a negative result in the Far-Western analysis cannot be interpreted because it could be due to a failure to renature a domain of a smaller TAF required for TBP binding. Also, functionally significant interactions between TBP and smaller TAFs might occur, but not be sufficiently stable to be demonstrated by this technique.

On the basis of a comparison of the DNase I footprint produced by holo-TFIID on the adenovirus major late promoter to the footprint produced by isolated TBP, we proposed a model in which TBP is not at the center of the holo-TFIID complex, but rather at one side (Zhou et al. 1992). With the new information on the direct interactions between TBP and the 250- and 125-kD TAFs, we can modify this model, placing the two largest TAFs at the center of the multisubunit complex, with the smaller TAFs and TBP bound to their surfaces (Fig. 6). This diagram also emphasizes the finding that the amino-terminal domain of TBP does not make any significant contacts with TFIID TAFs or with promoter DNA. Further analyses of holo-TFIID should indicate

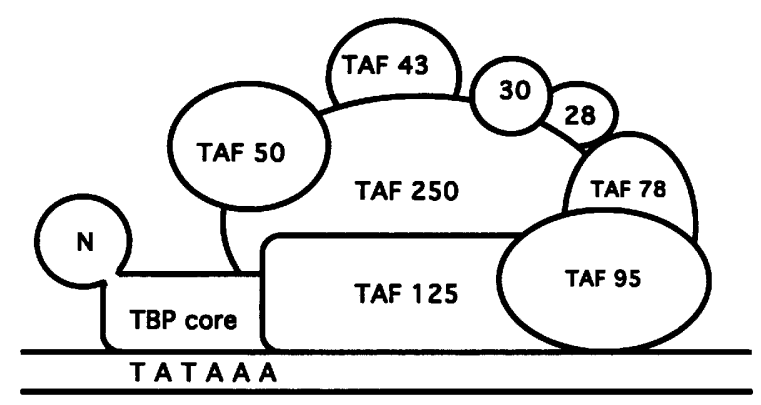

Figure 6. Model of holo-TFIID. The diagram is drawn to emphasize the interaction of the TBP carboxy-terminal core domain with $\mathrm{TAF}_{250}$ and $\mathrm{TAF}_{125}$, and the lack of interaction of the TBP amino-terminal domain with TFIID-TAFs or DNA. The complex is shown extending downstream from the TATA box on promoter DNA, in accordance with earlier footprinting results (Zhou et al. 1992). The arrangement of TAFs in the complex and the association of TAF 125 with DNA is purely hypothetical. 
which TAFs interact with each other and with DNA downstream from the TATA box.

\section{Materials and methods \\ Construction of HeLa cells expressing e $\triangle N T B P$}

A gene encoding the $12 \mathrm{CA} 5$ epitope-containing sequence $M G Y$ PYDVPDYAV (Field et al. 1988) fused to residues 155-339 of human TBP was synthesized by PCR amplification of a TBP cDNA clone (Kao et al. 1990) using synthetic primers for introduction of the amino-terminal epitope and flanking EcoRI sites. The amplified DNA fragment was inserted into the EcoRI site of pSR $\alpha$ MSVtkneo (Muller et al. 1991) to create pLTRe $\Delta$ NTBP. A helper-free retroviral stock was prepared by cotransfection of COS cells with pLTRe $\triangle \mathrm{NTBP}^{-}$and pSV- $\Psi^{-}-\mathrm{A}-\mathrm{MLV}$ that contains $\Psi^{-}$MLV proviral sequences expressing an amphotropic coat cloned into an SV40-based expression vector. Calcium phosphate transfection precipitates containing $15 \mu \mathrm{g}$ of each plasmid were transfected into $2 \times 10^{6} \mathrm{COS}$ cells and media containing recombinant retrovirus was harvested at $48 \mathrm{hr}$ posttransfection. Freshly seeded HeLa S3 cells were infected and selection of G418-resistant clones was performed as described (Zhou et al. 1992). Clones were expanded in medium containing $200 \mu \mathrm{g} / \mathrm{ml} \mathrm{G} 418$ and screened by Western blotting of total cell protein using monoclonal antibody 12CA5, as shown in Figure 1. Clone 20 was selected, grown, and maintained in suspension in S-MEM plus $5 \%$ calf serum with $200 \mu \mathrm{g} / \mathrm{ml} \mathrm{G} 418$ in a volume of $500 \mathrm{ml}$. A 20-liter culture was grown in media without antibiotic; cells were harvested and used for preparation of e $\triangle$ NTBP.

\section{Affinity purification of e $\triangle N T F I I D$ complex}

Nuclear extract was prepared from clone 20 cells and fractionated by phosphocellulose chromatography as described (Dignam et al. 1983). One milliliter of the undialyzed $\mathrm{D}(1.0 \mathrm{M} \mathrm{KCl})$ fraction, $\sim 1 \mathrm{mg}$ protein $/ \mathrm{ml}$, was incubated with $0.1 \mathrm{ml}$ packed beads of protein A-Sepharose covalently coupled to monoclonal antibody $12 \mathrm{CA} 5$ with rotation at $4^{\circ} \mathrm{C}$ for $8 \mathrm{hr}$. Further steps in purification were as described for eTFIID complex in Zhou et al. (1992). Briefly, the protein A-Sepharose beads with bound complex were washed extensively with buffer containing $0.5 \mathrm{M} \mathrm{KCl}$, then with buffer containing $0.1 \mathrm{M} \mathrm{KCl}$, and then eluted in $0.1 \mathrm{ml}$ buffer containing $0.1 \mathrm{M} \mathrm{KCl}$ and $1 \mathrm{mg} / \mathrm{ml}$ peptide YPYDVPDYA at room temperature for $30 \mathrm{~min}$.

\section{In vitro transcription}

One hundred nanograms of template plasmid [pG5E4T /Carey et al. 1990), pZ 7 E4T (M. Carey, unpubl.), or plasmid VI (Smale et al. 1990) containing the Spl-binding sites of SV40 and the initiator promoter element of the terminal transferase gene, but lacking a TATA box] was incubated with $30 \mu \mathrm{g}$ fraction TFIIA, $60 \mathrm{ng}$ recombinant TFIIB, $12 \mu \mathrm{g}$ fraction polymerase II/E/F, and $10 \mu \mathrm{l}$ of e $\Delta$ NTFIID complex or eTFIID complex as indicated, with or without activator protein in $50 \mu l 60 \mathrm{~mm} \mathrm{KCl}, 7.5 \mathrm{~mm}$ $\mathrm{MgCl}_{2}, 12 \mathrm{mM}$ HEPES (pH 7.9), $10 \mathrm{~mm} \beta$-mercaptoethanol, $12 \%$ glycerol, $4 \%$ polyethylene glycol, and $0.6 \mathrm{~mm}$ of ATP, GTP, CTP, and UTP for $60 \mathrm{~min}$ at $30^{\circ} \mathrm{C}$. Fractions TFIIA and polymerase II/E/F were purified from HeLa cell nuclear extract by chromatography on phosphocellulose and DEAE-Sepharose as described by Lin and Green (1991). Recombinant TFIIB was purified from engineered Escherichia coli as described by $\mathrm{Ha}$ et al. (1991). Activator proteins were $100 \mathrm{ng}$ Gal4-AH purified from engineered $E$. coli as described by Lin et al. (1988); $200 \mathrm{ng} \mathrm{Zta}$ purified from engineered $E$. coli as described by Lieberman and Berk (1990); or Sp1 purified from HeLa nuclear extract by chromatography on Sephacryl S-300 followed by three passes over an oligonucleotide-affinity column as described by Kadonaga and Tjian (1986). Transcripts were quantitated by primer extension as described (Schmidt et al. 1989) using primers described in Zhou et al. (1992).

\section{Far-Western protein blotting}

Interactions between TBP and TFIID-TAFs were analyzed by a protein-blotting protocol described in detail in Lee et al. (1991). Briefly, eTFIID complex isolated, as described in Zhou et al. (1992), was subjected to SDS-gel electrophoresis, electrophoretically transferred to nitrocellulose, and subjected to a renaturation protocol by incubating the nitrocellulose filter in buffers containing decreasing concentrations of guanidine $\mathrm{HCl}$. The blot was then incubated at room temperature for $14 \mathrm{hr}$ in $10 \mathrm{ml}$ buffer CZ 0.05 [10 mM HEPES (pH 7.9), $50 \mathrm{mM} \mathrm{KCl}, 2.5 \mathrm{~mm}$ $\mathrm{MgCl}_{2}, 50 \mu \mathrm{M} \mathrm{ZnCl}, 50 \mu \mathrm{M}$ EDTA, 1 mM DTT, $8.5 \%$ glycerol] plus $100 \mu \mathrm{l}$ reticulocyte lysate containing ${ }^{35} \mathrm{~S}$-labeled TBP or TBP deletion mutants prepared by in vitro transcription-translation. The blot was then washed with $20 \mathrm{ml}$ buffer $\mathrm{CZ} 0.05$ for $20 \mathrm{~min}$ two times and autoradiographed at $-70^{\circ} \mathrm{C}$ with an intensifying screen for 1-2 days.

\section{Acknowledgments}

This work was supported by U.S. Public Health Service grant CA 25235. T.G.B. was supported by a fellowship from the American Cancer Society. We thank our colleagues at UCLA for useful comments on the manuscript.

The publication costs of this article were defrayed in part by payment of page charges. This article must therefore be hereby marked "advertisement" in accordance with 18 USC section 1734 solely to indicate this fact.

\section{References}

Berkenstam, A., M.d.M. Vivanco Ruiz, D. Barettino, M. Hirikoshi, and H.G. Stunnenberg. 1992. Cooperativity in transactivation between retinoic acid receptor and TFIID requires an activity analogous to E1A. Cell 69: 401-412.

Carey, M., Y.-S. Lin, M.R. Green, and M. Ptashne. 1990. A mechanism of synergistic activation of a mammalian gene by GAL4 derivatives. Nature 345: 361-364.

Cormack, B.P., M. Strubin, A.S. Ponticelli, and K. Struhl. 1991. Functional differences between yeast and human TFIID are localized to the highly conserved region. Cell 65: 341-348.

Courey, A.J. and R. Tjian. 1988. Analysis of Spl in vivo reveals multiple transcriptional domains, including a novel glutamine-rich activation motif. Cell 55: 887-898.

Dignam, J.D., P.L. Martin, B.S. Shastry, and R.G. Roeder. 1983. Eukaryotic gene transcription with purified components. Methods Enzymol. 101: 582-598.

Dynlacht, B.D., T. Hoey, and R. Tjian. 1991. Isolation of coactivators associated with the TATA-binding protein that mediate transcriptional activation. Cell 66: 563-576.

Field, J., J.-I. Nikawa, D. Broek, B. MacDonald, L. Rodgers, I.A. Wilson, R.A. Lerner, and M. Wigler. 1988. Purification of a ras-responsive adenyl cyclase complex from Saccharomyces cerevisiae by use of an epitope addition method. Mol. Cell Biol. 8: 2159-2165.

Gill, G. and R. Tjian. 1991. A highly conserved domain of TFIID displays species specificity in vivo. Cell 65: 333-340. 
Giniger, E. and M. Ptashne. 1987. Transcription in yeast activated by a putative amphipathic a helix linked to a DNA binding unit. Nature 330: 670-672.

Greenblatt, J. 1991. Roles of TFIID in transcriptional initiation by RNA polymerase II. Cell 66: 1067-1070.

Ha, I., W.S. Lane, and D. Reinberg. 1991. Cloning of a human gene encoding the general transcription factor IIB. Nature 352: 689-695.

Horikoshi, M., T. Yamamoto, Y. Ohkuma, P.A. Weil, and R.G. Roeder. 1990. Analysis of structure-function relationship of yeast TATA box binding factor TFIID. Cell 61: 1171-1178.

Kadonaga, J. and R. Tjian. 1986. Affinity purification of sequence-specific DNA binding proteins. Proc. Natl. Acad. Sci. 83: 5889-5893.

Kao, C.C., P.M. Lieberman, M.C. Schmidt, Q. Zhou, R. Pei, and A.J. Berk. 1990. Cloning a transcriptionally active human TATA binding factor. Science 248: 1646-1650.

Kelleher, R.J. III, P.M. Flanagan, D.I. Chasman, A.S. Ponticelli, K. Struhl, and R.D. Kornberg. 1992. Yeast and human TFIIDs are interchangeable for the response to acidic transcriptional activators in vitro. Genes \& Dev. 6: 296-303.

Lee, W.S., C.C. Kao, G.O. Bryant, X. Liu, and A.J. Berk. 1991. Adenovirus ElA activation domain binds the basic repeat in the TATA box transcription factor. Cell 67: 365-376.

Lieberman, P.M. and A.J. Berk. 1990. In vitro transcriptional activation, dimerization, and DNA-binding specificity of the Epstein-Barr virus Zta protein. J. Virol. 64: 2560-2568.

Lieberman, P.M., M.C. Schmidt, C.C. Kao, and A.J. Berk. 1991. Two distinct domains in the yeast transcription factor IID and evidence for a TATA box-induced conformational change. Mol. Cell Biol. 11: 63-74.

Lin, Y.-S. and M.R. Green. 1991. Mechanism of action of an acidic transcriptional activator in vivo. Cell 64: 971-981.

Lin, Y.-S., M.F. Carey, M. Ptashne, and M. R. Green. 1988. GAL4 derivatives function alone and synergistically with mammalian activators in vitro. Cell 54: 659-664.

Matsui, T., J. Segall, P.A. Weil, and R.G. Roeder. 1980. Multiple factors required for accurate initiation of transcription by RNA polymerase II. J. Biol. Chem. 255: 11992-11996.

Muller, A.J., J.C. Young, A.M. Pendergast, M. Pondel, N.R. Landau, D.R. Littman, and O.N. Witte. 1991. BCR first exon sequences specifically activate $B C R / A B L$ tyrosine kinase oncogenes of Philadelphia chromosome-positive human leukemias. Mol. Cell Biol. 11: 1785-1792.

Nikolov, D.B., S.-H. Hu, J. Lin, A. Gasch, A. Hoffman, M. Horikoshi, N.-H. Chua, R.G. Roeder, and S.K. Burley. 1992. Crystal structure of TFIID TATA-box binding protein. Nature 360: 40-46.

Peterson, M.G., N. Tanese, B.F. Pugh, and R. Tjian. 1990. Functional domains and upstream activation properties of cloned human TATA binding protein. Science 248: 1625-1630.

Poon, D., S. Schroeder, C.K. Wang, T. Yamamoto, M. Horikoshi, R.G. Roeder, and P.A. Weil. 1991. The conserved carboxyterminal domain of Saccharomyces cerevisiae TFIID is sufficient to support normal cell growth. Mol. Cell Biol. 11: $4809-4821$.

Pugh, B.F. and R. Tjian. 1990. Mechanism of transcriptional activation by Spl: Evidence for coactivators. Cell 61: 11871197.

- 1991. Transcription from a TATA-less promoter requires a multisubunit TFIID complex. Genes \& Dev. 5: 1935-1945.

1992. Diverse transcriptional functions of the multisubunit eukaryotic TFIID complex. J. Biol. Chem. 267: 679682.

Reddy, P. and S. Hahn. 1991. Dominant negative mutations in yeast TFIID define a bipartite DNA-binding region. Cell 65: 349-351.

Schmidt, M.C., Q. Zhou, and A.J. Berk. 1989. Spl activates transcription without affecting the DNA binding activity of the TATA box factor. Mol. Cell Biol. 9: 3299-3307.

Sharp, P.A. 1992. TATA binding protein is a classless factor. Cell 68: 819-821.

Smale, S.T. and D. Baltimore. 1989. The "initiator" as a transcription control element. Cell 57: 103-113.

Smale, S.T., M.C. Schmidt, A.J. Berk, and D. Baltimore. 1990 Transcription activation by $\mathrm{Sp} 1$ as directed through TATA or initiatior: Specific requirement for mammalian transcription factor IID. Proc. Natl. Acad. Sci. 87: 4509-4513.

Tamura, T., K. Sumita, I. Fujino, A Aoyama, M. Horikoshi, A. Hoffman, R.G. Roeder, M. Muramatsu, and K. Mikoshiba. 1991. Striking homology of the "variable" N-terminal as well as the "conserved core" domains of the mouse and human TATA-factors (TFIID). Nucleic Acids Res. 19: 38613865.

Tanese, N., B.F. Pugh, and R. Tjian. 1991. Coactivators for a proline activator purified from the multisubunit human TFIID complex. Genes \& Dev. 5: 2212-2224.

White, R.J. and S.P. Jackson. 1992. The TATA-binding protein: A central role in transcription by RNA polymerases I, II and III. Trends Genet. 8: 284-288.

Zhou, Q., M.C. Schmidt, and A.J. Berk. 1991. Requirement of acidic amino acid residues immediately amino-terminal to the conserved domain of Saccharomyces cerevisiae TFIID. EMBO J. 10: 1843-1852.

Zhou, Q., P.M. Lieberman, T.G. Boyer, and A.J. Berk. 1992. Holo-TFIID supports transcriptional stimulation by diverse activators and from a TATA-less promoter. Genes \& Dev. 6: 1964-1974. 


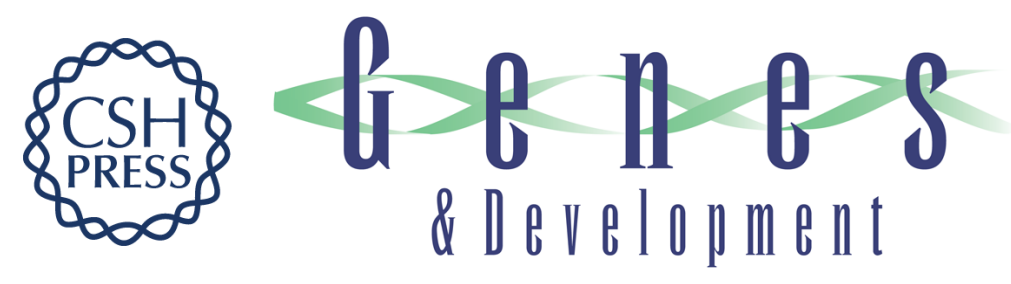

\section{Factors (TAFs) required for activated transcription interact with TATA box-binding protein conserved core domain.}

Q Zhou, T G Boyer and A J Berk

Genes Dev. 1993, 7:

Access the most recent version at doi:10.1101/gad.7.2.180

References This article cites 38 articles, 16 of which can be accessed free at: http://genesdev.cshlp.org/content/7/2/180.full.html\#ref-list-1

License

Email Alerting Service top right corner of the article or click here.

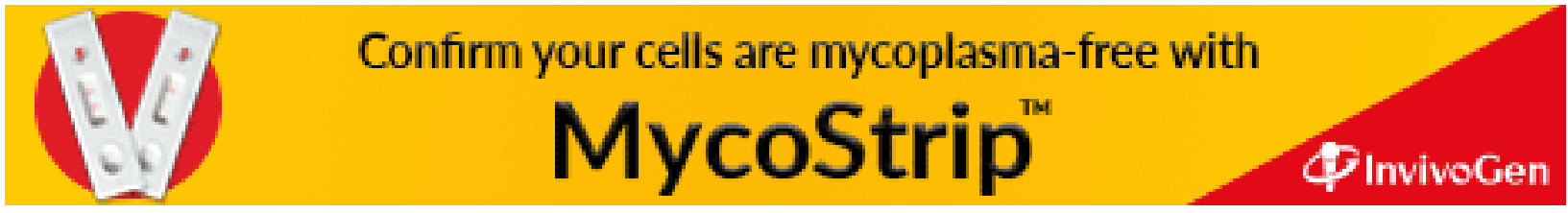

